\title{
Why 'believes' is not a vague predicate
}

\author{
Sophie Archer ${ }^{1}$
}

Published online: 17 October 2017

(C) The Author(s) 2017. This article is an open access publication

\begin{abstract}
According to what I call the 'Vagueness Thesis' ('VT') about belief, 'believes' is a vague predicate. On this view, our concept of belief admits of borderline cases: one can 'half-believe' something (Price in Belief, George Allen \& Unwin, London, 1969) or be 'in-between believing' it (Schwitzgebel in Philos Q 51:76-82, 2001, Noûs 36:249-275, 2002, Pac Philos Q 91:531-553, 2010). In this article, I argue that VT is false and present an alternative picture of belief. I begin by considering a case-held up as a central example of vague belief-in which someone sincerely claims something to be true and yet behaves in a variety of other ways as if she believes that it is not. I argue that, even from the third-person perspective prioritised by proponents of VT, the case does not motivate VT. I present an alternative understanding of the case according to which the person in question believes as they say they do yet also has a belief-discordant implicit attitude otherwise. Moreover, I argue that, independently of the interpretation of any particular case, VT fails to accommodate the first-person perspective on belief. Belief is not only an item of one's psychology that helps explain one's behaviour; it is what one takes to be true. This fact about belief manifests itself in the nature of deliberation concerning whether to believe something and that of introspection regarding whether one believes something. Attending to these phenomena reveals that VT is not merely unmotivated, but untenable.
\end{abstract}

Keywords Belief · Half-belief · In-between belief · Implicit bias · Transparency

Sophie Archer

sophie.archer@philosophy.ox.ac.uk

1 Keble College, University of Oxford, Oxford OX1 3PG, UK 


\section{Introduction}

Belief attribution is not always easy. In fact, there are lots of different kinds of cases in which it is extremely contentious what someone believes. Imagine someone who ordinarily avoids walking under ladders because of the associated bad luck but who, when about to miss her train, runs straight under one without hesitation. Or, someone who sincerely prays to God in church on Sundays but lives an apparently secular life for the rest of the week. Price (1969) uses these kinds of examples in order to motivate his view that it is possible to 'half-believe' something-that walking under ladders is unlucky or that God exists, for example. More recently, Schwitzgebel $(2001,2002,2010)$ has presented a similar range of cases which he insists are best interpreted in terms of 'in-between belief'. In this article I will argue, contra Price and Schwitzgebel, that 'believes' is not a vague predicate.

I will open in Sect. 2 by outlining the 'Vagueness Thesis' ('VT') I am opposing in more detail. In Sect. 3, I will begin my critique of VT by examining one of Schwitzgebel's central motivating cases from the third-person perspective of the belief attributor prioritised by Price and Schwitzgebel: the case of Juliet, who sincerely claims something to be true and yet behaves in a variety of other ways as if she believes that it is not. I will argue that, even from the third-person perspective, the case does not motivate VT, which is naturally understood in terms of Juliet's believing as she claims and yet possessing a belief-discordant implicit attitude in addition to her belief. Furthermore, I will argue that there is a moral to be extracted from my discussion of VT's interpretation of this case, which generalises to other cases cited by Price and Schwitzgebel. At any given time, each person has an uncountably large number and a wide variety of mental states which, taken together, help explain their behaviour. Their complicated behavioural output can readily be understood, even from the third-person perspective, in terms of many states, which sometimes interact and overlap. As such, their behaviour does not motivate the idea that it is vague whether or not they believe something. Nonetheless, for all that I will say in this second section, VT is simply unmotivated by a central case and some others like it. It remains tenable and potentially motivated by some other kind of case. It is in Sect. 4 that I will turn to arguing that VT is untenable. I will maintain that belief is a janus-faced phenomenon. On the one hand, from the third-person perspective, a belief is a psychological state that helps explain the believer's behaviour. On the other, from what I will call the 'first-person perspective', a belief is the believer's view on the world: what they take to be true. ${ }^{1}$ Any satisfactory account of belief must accommodate both of these faces. As I will have argued, VT is unmotivated even when it comes to accommodating belief's third-personal face, with which it is concerned. But as I will argue in Sect. 4, it is untenable when it comes to accommodating belief's first-personal face. In the final analysis, it is VT's inability to accommodate the first-person perspective on belief that decides between

\footnotetext{
1 Strictly, on my view, one's belief is what one takes to be true in a certain manner, namely, in a manner that is correct if and only if its contents are true (see Archer 2017). In what follows I will simply talk about what one 'takes to be true' as shorthand for the completed version.
} 
an interpretation of a case such as Juliet's involving vague belief and an interpretation such as my own, which does accommodate belief's first-personal face.

\section{2 'Believes' as a vague predicate}

Vagueness is the phenomenon of imprecise classification. If a term is vague, it has what we might call 'borderline' cases. 'Bald' is a classic example. If it is vague whether to say of a particular individual that they are 'bald', this is because there is no precise number of hairs they need have (or lack) in order to count as bald. It is possible to be a bit bald or 'balding' as one might more naturally put it in English. 'VT' is the claim that 'believes' is vague. According to VT our concept of belief admits of borderline cases: one can 'half-believe' something or be 'in-between believing' it.

Price (1969, p. 302) claims:

We quite often say of another person that he half-believes such and such a proposition though he does not wholly believe it. Sometimes we even say such things about ourselves, usually in the past tense. 'I see now that at that time I only half-believed what he told me.' I did not quite believe it, but I did not disbelieve it; and yet I was not in a state of suspended judgement about it either. My attitude was one which came fairly close to believing and yet did not go all the way; or it had some of the characteristics of believing, but lacked others.

According to Price (1969, p. 312):

A half-belief... seems to be something which is 'thrown off' when circumstances alter. In some sorts of contexts one is in a belief-like state with regard to a proposition, but in others one disbelieves it or just disregards it.

More recently, Schwitzgebel (2001, 2002, 2010) has presented a very similar position according to which there are cases that:

...should be regarded as 'in-between' cases of believing, in which it's neither quite right to ascribe the belief in question nor quite right to say that the person lacks the belief. (Schwitzgebel 2010, p. 531)

However, his position is more ambitious than Price's. Schwitzgebel thinks that cases in which someone appears to believe something in one context and then not in another are just one kind of example of in-between believing. Cases like 'Juliet' represent another:

[Juliet is]... a Caucasian-American philosophy professor. [She]... has critically examined the literature on racial differences in intelligence, and...finds the case for racial equality compelling. She is prepared to argue coherently, sincerely, and vehemently for equality of intelligence and has argued the point repeatedly in the past. And yet... [she] is systematically racist 
in most of her spontaneous reactions, her unguarded behaviour and her judgments about particular cases... Juliet could even be perfectly aware of these facts about herself; she could aspire to reform; self-deception could be largely absent. We can imagine that sometimes Juliet deliberately strives to overcome her bias in particular cases. She sometimes tries to interpret black students' comments especially generously. But it's impossible to constantly maintain such self-conscious vigilance, and of course patronizing condescension, which her well-intentioned efforts sometimes become, itself reflects apparent implicit assumptions about intelligence. (Schwitzgebel 2010, p. 532)

Whether or not Juliet appears to believe that the races are intellectually equal does not simply vary from context to context:

...it seems possible for Juliet in a single moment both to be having a racist reaction and to be sincerely judging that the races are intellectually equal - for example, when she's having a racist reaction and trying to suppress it or when she' s grading a black student's essay on intellectual equality, undervaluing the essay but regarding its conclusions as true. (Schwitzgebel 2010, p. 543)

Indeed, Schwitzgebel thinks that belief's vagueness is revealed by a great many more types of case besides those involving contextual variation and cases of implicit bias such as Juliet's. Other examples include those involving partial forgetting such as a partially forgotten phone number, cases of self-deception, and cases of what Schwitzgebel (2002, p. 265) calls 'peripheral ignorance' such as that of Kripke's (1979) Pierre who will assent to the sentence 'Londres est jolie' but also to the sentence 'London is ugly', not realising that 'Londres' and 'London' refer to the same city. ${ }^{2}$

VT, as I will be understanding it then, is not restricted in application to cases in which whether someone believes something appears to vary from context to context. Rather, according to VT, it is vague whether or not someone believes something under any circumstances in which they satisfy the criteria for holding the belief in question to some significant extent, but not sufficiently to count as believing it simpliciter. ${ }^{3}$ VT is compatible with different views regarding the metaphysics of belief, as Schwitzgebel (2010, pp. 535-536) points out. Price and Schwitzgebel are

\footnotetext{
${ }^{2}$ Schwitzgebel (see e.g. 2002, p. 264), unlike Price (1969, pp. 302-304), includes degrees of belief, or 'credences' as they are sometimes called, as a type of vague belief. It is important to note, however, that in denying VT I do not commit myself to denying the reality of degrees of belief. For example, it is coherent to maintain that one who holds credence 0.6 in a proposition simply does not believe it outright; it is not vague whether or not they do. Rowbottom $(2007,2016)$ argues, contra Schwitzgebel, that Juliet's case - that I will soon be discussing - should be understood as involving (sometimes rapidly) fluctuating degrees of belief in response to changes in information, mood, or other attitudes, or a combination of these variables. Schwitzgebel understands the disagreement between himself and Rowbottom as one about which kind of vague belief can account for Juliet's case: the degrees of belief kind or another kind. But it need not be understood in this way. It can be understood as a debate about whether or not Juliet's belief is vague or whether she has fluctuating degrees of belief (not understood as a type of vague belief).

3 There is of course a worry here about how to understand 'significant' and 'sufficiently'. Schwitzgebel (e.g. 2002, p. 253) claims that these are matters to be determined by the belief ascriber but this does not strike me as a claim to which VT is necessarily wed.
} 
both dispositionalists about belief. They think that what it is to believe something is to satisfy what Schwitzgebel (e.g. 2002, p. 251) calls a "dispositional stereotype": roughly, to be disposed to behave in various ways associated with that belief. (For Price and Schwitzgebel, this includes dispositions to behave 'internally' in certain ways, such as the disposition to 'inwardly assent' to the content of the belief in question, to feel surprise upon discovering its falsity etc.) Dispositionalism appears to lend itself to VT, which translates on a dispositionalist metaphysics as the claim that if someone possesses a significant number of the dispositions pertinent to their holding a particular belief (bearing in mind that some dispositions are more central to the stereotype than others), but not sufficiently many to count as believing it simpliciter, it is vague whether or not they believe it. A functionalist metaphysics of belief seems to sit equally comfortably with VT. For a functionalist about belief, roughly speaking, what it is to believe something is to be in a state that occupies a certain functional role, so VT translates as the claim that if someone's state occupies this role to some significant extent but not sufficiently for belief simpliciter it is vague whether or not they hold the belief in question. Pairing VT with representationalism is slightly more forced. If believing that $p$ constitutively involves representing that $p$ in a certain way, a vague belief would need to involve some kind of partial representation. In the discussion that follows, I will attempt to discuss VT independently of any particular metaphysics of belief. The discussion of Juliet's case centres on her (external) behaviour but can be interpreted variously depending upon one's metaphysics. For dispositionalists such as my opponents the discussion is one about Juliet's dispositions to behave, understood as constituting either her vague belief or her belief. But for a representationalist about belief, for example, the discussion of Juliet's behaviour and which dispositions to behave she possesses can be understood as a discussion of the evidence regarding her belief state. Before I turn to this discussion, it is important to note that according to VT, just as growth from any given hair follicle is neither necessary nor sufficient for categorising someone as 'not bald', whatever the criteria for $S$ 's believing that $p$ are understood to be, meeting any individual criterion is neither necessary nor sufficient for $S$ 's believing that $p$. As Schwitzgebel (2002, p. 252) puts it in accordance with his dispositionalist metaphysics:

No one disposition is either necessary or sufficient for the possession of any belief.

\section{Juliet, from the third-person perspective}

Both Price and Schwitzgebel cite a wide variety of cases in support of VT, far too many to do justice to here. Rather than try, my approach in this section will be to focus on one of Schwitzgebel's central motivating cases and argue in detail that, even from the third-person perspective on belief prioritised by Price and Schwitzgebel, the case does not motivate VT. Nonetheless, I will conclude the section by discussing a moral that can be drawn from my treatment of this case, which generalises to some of the other cases cited by Price and Schwitzgebel. 
According to Schwitzgebel, Juliet, the implicit racist, provides us with a prime example of the vagueness of belief. She resembles someone who believes that the races are intellectually equal to some significant extent but not enough to classify her as holding the belief simpliciter: it is vague whether or not she believes that they are. I will begin my case against this interpretation by arguing that she does not simply resemble someone who believes that the races are intellectually equal in some ways and not in others. There is a pattern in her behaviour, which simply claiming it to be vague whether or not she believes that the races are intellectually equal fails to capture. What is the pattern in Juliet's behaviour? In reflecting upon whether or not the races are intellectually equal, Juliet consistently behaves as if she believes in the intellectual equality of the races. She argues the point "coherently, sincerely, and vehemently" and even makes attempts to bring the rest of her behaviour into line. In reflecting upon the question at hand she would never behave as if she lacked the belief that the races are intellectually equal. And in the rest of her behaviour-which does not involve her reflecting on the question as to whether the races are intellectually equal-she mostly fails to resemble one who believes that they are. All of Juliet's behaviour in reflecting upon the question at hand hangs together, as does most of her behaviour in not reflecting on this question. Furthermore, in not reflecting upon this question, for the most part, it is not as if Juliet simply fails to resemble one who believes that the races are intellectually equal. In fact, she behaves as if she is positively of the view that the races are not intellectually equal.

Merely claiming it to be vague whether or not Juliet believes that the races are intellectually equal does nothing to explain her behaviour that points to her being positively of the opposing view. Furthermore, all that the claim that it is vague whether she believes that the races are intellectually equal involves is that she resembles such a believer in some ways and not in others, it does not specify which. So, it is consistent with its being vague whether she holds the belief in question that on some occasions Juliet asserts it to be false that the races are intellectually equal, on others, argues for the opposite conclusion, for example.

Insofar as it is true of Juliet that she resembles someone who believes that the races are not intellectually equal to some extent, VT would presumably be committed to claiming that it is vague whether or not she believes this too. But regardless as to whether the claim is that it is vague whether or not Juliet believes that the races are intellectually equal or that in addition to this it is vague whether or not she believes that it is not the case that this is so, the pattern in Juliet's behaviour remains unexplained. Augmenting the picture with an additional vague belief gets us no closer to capturing the pattern in Juliet's behaviour. Again, it is consistent with claiming that it is vague whether she possesses both of the contradictory beliefs in question that some of her behaviour in reflecting upon whether or not the races are intellectually equal points in the direction of her believing that they are and some in the direction of her believing that they are not. But Juliet does not behave in such an apparently random fashion.

In failing to capture the pattern in Juliet's behaviour, simply appealing to vague belief also fails to capture what is normatively problematic about Juliet's case. Not only does she behave in some respects as if she believes that the races are 
intellectually equal and in some respects as if she believes that they are not, this is indicative of what is normatively problematic about her situation. Indeed, she recognises this: she aspires to reform, to bring all of her behaviour into line with her judgement that the races are intellectually equal. ${ }^{4}$

I will now present an alternative understanding of Juliet's case which, pace Schwitzgebel, does do justice to her normatively problematic behavioural pattern. This is what Schwitzgebel (2010) calls the "pro-judgment view" but I will call the 'belief-implicit attitude' picture. On this picture, Juliet does believe that the races are intellectually equal simpliciter but, in addition to this belief, she has some kind of implicit attitude to the effect that they are not. There is a growing literature devoted to trying to understand the precise nature of the kind of implicit attitude involved in implicit bias cases such as Juliet's. Zimmerman (2007) claims them to be habits. Tamar Gendler (e.g. 2008, p. 552) famously calls them 'aliefs'; an alief is "...an innate or habitual propensity to respond to an apparent stimulus in a particular way". Levy (2015) thinks that they should rather be thought of as nonassociational 'patchy endorsements'. I will not attempt to settle the question as to the precise naure of Juliet's implicit attitude here. ${ }^{5}$

On my proposed belief-implicit attitude understanding of her case, Juliet does believe that the races are intellectually equal simpliciter: she is disposed to behave in all of the ways one who believes that the races are intellectually equal is disposed to behave. However, only some of these dispositions- to assert that they are, to argue that they are etc.- - are actualised. Some of the relevant dispositions to behave-those that pertain to her behaviour in not reflecting upon the question of the intellectual equality of the races - are not actualised. But there is an explanation as to why they are not actualised. They are not actualised because in addition to Juliet's belief that the races are intellectually equal she also possesses a beliefdiscordant implicit attitude that blocks her dispositions to behave as if she believes that the races are intellectually equal when not reflecting upon the question at hand. The implicit attitude in this case in fact causes her to behave as if she is of the opposing view. Any plausible dispositional attribution must include a ceteris paribus clause, such that the disposition in question is only expected to be actualised all else being equal (as Schwitzgebel of course acknowledges). The suggestion here is that not all of Juliet's dispositions to behave associated with her belief that the

\footnotetext{
${ }^{4}$ Borgoni (2016, pp. 51-52) wonders whether Juliet's normative difficulties might be understood in accordance with VT in terms of her failure to fully form the belief that the races are intellectually equal. Juliet should believe this simpliciter (on the basis of her epistemic reasons) and yet it is merely vague whether she does. I agree with Borgoni that this attempt to capture what is normatively problematic about Juliet's situation does not seem to get her case right. Her normative difficulties lie in the conflict manifested in the fact that some of her behaviour suggests that she believes that the races are intellectually equal and some that she positively regards them as not being so.

5 Some even argue that the implicit attitudes in question are beliefs (see e.g. Borgoni 2016; Mandelbaum 2016). Of course, much more would need to be said about the detail of this belief-implicit attitude picture in order to fully account for why Juliet behaves as she does. Nonetheless, we have an outline of an explanation of the pattern in Juliet's behaviour (on which I will shortly elaborate further), which simply appealing to a vague belief on her part, or even two vague beliefs, is incapable of providing.
} 
races are intellectually equal are actualised because all else is not equal for Juliet; in addition to her belief, she has a belief-discordant implicit attitude. ${ }^{6}$

On my view, Juliet's case is comparable with a case that I will call 'Precipice', versions of which were discussed by the early moderns (see e.g. Hume 1978, p. 100; Montaigne 1957, p. 250). Here is Gendler's (2008, p. 634) contemporary example:

In March 2007, 4000 feet above the floor of the Grand Canyon, a horseshoeshaped cantilevered glass walkway was opened to the public. Extending 70 feet from the Canyon's rim, the Grand Canyon Skywalk soon drew hundreds of visitors each day...' [who know]... what sensation is being promised... The promise is the dizzying thrill of vertigo. And indeed, last week some visitors to this steel supported walkway anchored in rock felt precisely that. One woman, her left hand desperately grasping the 60-inch-high glass sides and the other clutching the arm of a patient security guard, didn't dare move toward the transparent center of the walkway.' (Rothstein, The New York Times, 19th May 2007)

In defending the claim that Juliet and Precipice are comparable, I will now defend my claim that there is a significant pattern in Juliet's behaviour against Schwitzgebel's (2010) denial that this is so.

One might think that the proponent of VT would claim it to be vague whether the woman here believes herself to be safe. She resembles someone who does in some important ways - she gets up on the walkway in the first place, for example-but not entirely-she won't dare move towards the centre. However, just as with Juliet, there is a pattern in this woman's behaviour that the claim that it is vague whether she believes herself to be safe would not capture. In this case, the key instance of relevant reflective behaviour is the fact that she puts herself in this situation. And yet, analogously to Juliet, not only does she fail to resemble someone who believes herself to be safe, she also behaves unreflectively largely as if she is positively of the view that she is unsafe, she grasps the sides, clutches the security guard's arm, and won't dare move towards the centre. Just as in Juliet's case, this behaviour is

\footnotetext{
${ }^{6}$ Precisely how to understand ceteris paribus clauses is a complex and controversial matter. My thanks to an anonymous referee for this journal for encouraging me to discuss the matter in a little more depth here. Schurz (2002) suggests distinguishing between a 'comparative' understanding of when a ceteris paribus clause can be invoked and an 'exclusive' one. On a comparative understanding, a ceteris paribus clause added to the conditional statement of a disposition requires that phenomena not mentioned in either the antecedent or the consequent remain unchanged. On an exclusive understanding, a ceteris paribus clause requires that certain phenomena are not present. I have the latter understanding of ceteris paribus clauses in mind. All else is not equal for Juliet not necessarily in the sense that some other factor has changed, but rather in the sense that there is some interfering factor: her implicit attitude. Schwitzgebel (2002, pp. 253-257) seems to have a similar understanding of ceteris paribus clauses in mind. Furthermore, in discussing the kinds of "excusing conditions" that legitimate the invocation of a relevant ceteris paribus clause, he of course includes the existence of other mental states, such as a desire, for example (e.g. p. 254). But he notes: “...of course there must be limits to such excusers. Otherwise, we could save any generalization or dispositional ascription we wished simply by excusing every counterinstance. Articulating the principles underwriting the limits on excusing conditions is a difficult task... (I'd say, roughly, that when a candidate excusing condition would undermine the potential usefulness of the generalization we should reject it as an excuser.)" (Schwitzgebel 2010, p. 534) I will now argue that Juliet's implicit attitude passes this test for legitimate excusing conditions.
} 
suggestive of two mental states at work. In this case, the woman believes that she is safe simpliciter but some of her dispositions to behave as if she is are blocked from being actualised by her instinctive fear at such a great height. This fear explains her grasping the sides, clutching the security guard's arm and not daring to move towards the centre.

Interestingly, Schwitzgebel (2010, p. 549) admits in a footnote that Precipice is not a case of vague belief:

I would not deny that the man who stands trembling on a glass floor high in the air still believes that the glass floor is solid and can support him, to use one of Gendler's examples. The difference between this case and the cases I've presented is that in my cases there is a broad range of dispositions that deviate from the dispositional profile characteristic of the endorsed judgment, while in the glass-floor case the deviation is narrow and arguably excused. Especially relevant here are cognitive dispositions - dispositions to make certain inferences and to reach certain related judgments (e.g. in Juliet's case about the quality of an applicant or student) that show little parallel between the two types of case.

So, Schwitzgebel claims that Precipice and Juliet are importantly different. In particular, he points to the fact that Juliet makes certain inferences and judgements - for example regarding the quality of an individual applicant or student - that deviate from those she would make were she to believe the races to be intellectually equal simpliciter. Schwitzgebel's (2010, p. 541) thought, which he emphasises elsewhere, is that it is not as if there is a neat divide between all of Juliet's automatic behaviour and all of her judgements and reflective behaviour. She judges that the races are intellectually equal consistently, but she also makes judgements in specific cases, such as 'This student doesn't seem very bright', which are out of keeping with her view on the intellectual equality of the races. It is not just her knee-jerk behaviour that fails to fall into line. Similarly, we can imagine that sometimes she responds unthinkingly as if the races are intellectually equal too. So, on Schwitzgebel's view, Precipice is distinct from Juliet insofar as in Precipice, unlike Juliet, there is a neat pattern of 'narrow' deviation from the behaviour we would expect such that the woman can still be said to believe that she is safe but is also simply afraid.

However, the pattern I have identified in Juliet's behaviour is not one in which all of her reflective behaviour hangs together, as do all of her knee-jerk reactions. It is more subtle than that. Rather, my claim is that in reflecting on the question of the intellectual equality of the races, Juliet consistently behaves as if the races are intellectually equal. She would never assert that this is not so, for example. Furthermore, most of her unreflective behaviour is as if she is positively of the view that the races are not intellectually equal. This is the pattern in Juliet's behaviour that the claim that it is vague whether or not Juliet believes that the races are intellectually equal does not help us capture. Appealing to a belief simpliciter plus some kind of belief-discordant implicit attitude does capture the pattern. 
But why the subtlety in the pattern? Why does Juliet sometimes make 'racist' judgements and sometimes react automatically in an egalitarian manner? ${ }^{7}$ Let's $^{\text {' }}$ begin with the former. Juliet's judgement that a particular black student 'doesn't seem that bright' for example, is entirely compatible with the belief-implicit attitude picture. Indeed, the belief-implicit attitude picture has an explanation of such judgements that merely claiming Juliet has one (or two) vague beliefs lacks: namely, these judgements are influenced, outside of Juliet's conscious awareness, by her implicit attitude. Pace Schwitzgebel (2010, pp. 538-541), the belief-implicit attitude picture of Juliet's case does not fail to recognise that beliefs are not always (or perhaps not even for the most part) pure responses to one's epistemic reasons (those reasons that one understands to pertain to the truth of the matter). On Schwitzgebel's view, according to the belief-implicit attitude picture, a line is drawn between all of Juliet's reflective behaviour and all of her automatic responses and her reflective behaviour is simplistically understood to be purely responsive to her epistemic reasons and therein tied to belief. However, as I have just explained, the pattern I have identified is not a straightforward divide such that all of Juliet's reflective behaviour hangs together in contrast to all of her automatic behaviour. But neither is the belief-implicit attitude picture committed to conceiving of all of Juliet's judgements as formed purely on the basis of her epistemic reasons. The influence of her implicit attitude upon some of her judgements-that the black student 'doesn't seem that bright', for example—may be a case in point.

As for Juliet's egalitarian unthinking behaviour, again, this is perfectly in keeping with the view that she believes that the races are intellectually equal and yet has a belief-discordant implicit attitude otherwise. After all, one's beliefs express themselves in one's unthinking behaviour. Indeed, in the 'good' case, where there is no conflicting attitude, I simply believe that $p$ and all of my relevant behaviour (both reflective and otherwise) evinces this belief; all of my dispositions to behave associated with this belief are actualised. Nonetheless, in Juliet's case, a significant portion of her unreflective behaviour (as well as some judgements about particular cases, as we have seen) betray her implicit attitude to the effect that the races are not intellectually equal. ${ }^{8}$

It is important to stress that on the belief-implicit attitude picture of Juliet's case I am defending, someone's unreflective behaviour is pertinent to whether or not they believe something. Indeed, someone who believes that $p$ is answerable for whether or not they behave unreflectively as if they do. Pace Schwitzgebel (see e.g. 2010, pp. 538-541), the view, as I am understanding it, is not committed to some kind of 'intellectualism' about belief, such that one's unreflective behaviour is of no

\footnotetext{
7 I put 'racist' in quotation marks here as whether to attribute racism proper in cases of implicit bias such as Juliet's is controversial and intimately connected to the question as to the nature of the attitudes held by the person in question (see Levy 2015).

${ }^{8}$ As an anonymous referee for this journal pointed out, it is of course trivially true that someone's behaviour always falls into some pattern or other and there may be some legitimate disagreement as to whether a particular pattern is sufficiently suggestive of a given combination of mental states. Nonetheless, in Juliet's case I think the pattern in her behaviour is sufficiently suggestive of the beliefimplicit attitude picture.
} 
consequence when it comes to what one believes. My suggestion is not that it is clear from Juliet's behaviour that she is merely disposed to behave as if she believes that the races are intellectually equal when reflecting upon the question at hand and that this is sufficient for attributing to her the belief that the races are intellectually equal regardless of all of her other behaviour. As aforementioned, on the beliefimplicit attitude view, Juliet does possess all of the dispositions to behave as if she believes that the races are intellectually equal simpliciter but some of them are blocked from being actualised. And, indeed, as the belief-implicit attitude view acknowledges, her case is normatively problematic insofar as this is so.

So, I have argued that there is a significant pattern in Juliet's behaviour that the belief-implicit attitude picture can make sense of and that in so doing it is not committed to the claim that beliefs are formed solely on the basis of epistemic reasons or that a person's unreflective behaviour is of no consequence when it comes to belief attribution. Before I conclude this section with an eye to some of Price and Schwitzgebel's other cases, it is important to address a potential line of response on behalf of VT.

Attributing dispositions to behave on the basis of actual behaviour is a delicate matter under any circumstances and one might worry about the grounds for claiming that Juliet posesses all of the dispositions to behave associated with the belief that the races are intellectually equal. Perhaps, as I have argued, one must acknowledge that the pattern in Juliet's behaviour reveals that she possesses some kind of implicit attitude to the effect that the races are not intellectually equal. But why must one accept that this attitude serves to block the actualisation of certain of her dispositions to behave associated with her belief that the races are intellectually? Couldn't the proponent of VT maintain instead that Juliet's implicit attitude prevents her from possessing some of the dispositions associated with the belief that the races are intellectually equal? I have maintained that Juliet has all of the dispositions to behave associated with the belief that the races are intellectually equal but some of them are not actualised. But why not maintain, as Schwitzgebel does, that she only possesses some of the dispositions associated with the belief that the races are intellectually equal, all of which are actualised? After all, if her implicit attitude can explain why certain of Juliet's dispositions to behave associated with her belief are not actualised, could it not explain why she fails to possess them at all? ${ }^{9}$

First, it is far from obvious that a vague belief combined with a discordant implicit attitude can adequately capture the normative conflict inherent in Juliet's case. Second, even if this interpretation were consistent with Juliet's case, her case still could not be understood to motivate VT. The belief-implicit attitude picture provides us with an explanation as to how Juliet can behave as she does that is consistent with her believing that the races are intellectually equal simpliciter. It teaches us that we do not need to appeal to her belief's being vague to understand her behaviour. ${ }^{10}$

\footnotetext{
9 My thanks to Jonathan Way and Joseph Schear for both independently putting this idea to me.

10 Rowbottom (2016) has recently argued that the presence of certain attitudes, such as fears and desires for example, or changes in mood, can cause changes in one's dispositional profile qua believer at a certain time (which he understands in terms of one's degree of belief fluctuating). Perhaps Juliet's implicit
} 
This completes my case against the idea that Juliet can be used to motivate VT. Schwitzgebel treats Juliet's case as a central motivating case for VT. Nonetheless, the many different types of case that he cites as examples of vague belief form a rag bag set. As I mentioned at the outset, he includes cases of partial forgetting, those that involve Kripke's Puzzle and many more besides. On my view, there is nothing that unites all of these types of case. Nonetheless, I do think that there is a moral to be extracted from my discussion of Juliet's case, which generalises to some of the other cases offered in support of VT. I have argued that Juliet's behavioursimilarly to that of the woman in Precipice-is naturally accounted for by attributing to her two interacting states. My suspicion is that one of the features of our mental life that VT fails to appreciate, generally speaking, is that at any given time each person has an uncountably large number and a wide variety of mental states, which, taken together, help explain their behaviour. If, per impossible, an individual had only one belief, they would behave in a manner that was entirely in keeping with what we would expect of someone who believed the content of that belief (and only believed the content of that belief). But as human beings really are, their implicit attitudes, fears, anxieties, hopes, etc. complicate the behavioural output of their beliefs. Their complex behaviour does not support the conclusion that it is vague whether or not they hold a certain belief. An individual who believes that $p$ will, more often than not, fail to present as a perfect exemplar of one who believes that $p$ simply in virtue of the fact that they have lots of other mental states in addition to this belief that interact with the belief in lots of complicated ways. ${ }^{11}$

\section{Footnote 10 continued}

attitude changes which of the dispositions relevant to whether or not she believes that the races are intellectually equal she possesses over time rather than merely blocking their actualisation. My thanks to an anonymous referee for this journal for highlighting this interpretation of Juliet's case. Similarly to attributing Juliet a vague belief and an implicit attitude, it is unclear that attributing her a fluctuating dispositional profile qua believer and an implicit attitude can capture her normative conflict and, regardless, there is no need to appeal to such fluctuations when the belief-implicit attitude picture adequately captures her case.

11 Rowbottom (2007, p. 135) makes this point with an adapted version of an example of Ryle's (1949, pp. 134-135):

" $[\mathrm{A}]$ to be unhesitant in telling oneself and [B] others that it is thin, $[\mathrm{C}]$ in acquiescing in other people's assertions to that effect, [D] in objecting to statements to the contrary, [E] in drawing consequences from the original proposition, and so forth. But it is also $[\mathrm{F}]$ to be prone to skate warily, $[\mathrm{G}]$ to shudder, $[\mathrm{H}]$ to dwell in imagination on possible disasters and [I] to warn other skaters...

But now take the individual who has dispositions A, E, F, G, \& H, yet not B, C, D, \& I. A credible explanation is that he is a nasty prankster who is sure that the ice is dangerously thin, but would delight in seeing someone else fall through it!"

The pattern present in this case suggests that it is not vague whether or not the person believes the ice to be thin, but that they do believe this and intend to deceive others about the fact. As an anonymous referee for this journal pointed out, if the person in question here did straightforwardly intend to deceive others, this intention would show up in a more extensive description of their dispositions, including more of their 'internal' dispositions in particular. The same may be true of the woman's fear in Precipice, for example, and of the relevant mental states in some of the other cases I am about to discuss. However, this does not undermine the argument against VT that the cases as described already exhibit patterns that undermine the motivation for the vague belief account-Rowbottom's case already suggests that the person believes and intends to deceive, for example. 
Consider Price's example, with which I began, of someone who ordinarily avoids walking under ladders but who, when about to miss their train, runs straight under one without hesitation. Similarly to Juliet and the woman in Precipice, there is a pattern in this person's behaviour: it is only when it really matters-when pressed for time, for example - that they will walk under a ladder, otherwise, they will avoid doing so. VT alone has no resources to explain such a pattern. On my view, the person in question believes that walking under ladders will do them no harm but they also harbour a suspicion that it is unlucky to do so. Similarly, I think some of Price's (1969, pp. 307-312) examples of 'Aesthetic Half-Belief' are naturally understood in terms of a belief plus another, complicating attitude. On my view, someone who is 'carried away' by a play, for example, believes the action on stage to be fictitious. As Price (1969, p. 311) notes:

When the heroine falls into the clutches of the villain, he does not rush out of the theatre and ring up the police.

Nonetheless, he is imaginatively engaged with the play, such that he really cries for the heroine's sake, for example. Again, it is the combination of the belief that what is taking place is fictitious and his imagining that it is not, which naturally captures the precise pattern in his behaviour: why he behaves as if the events were taking place in the respects he does and as if they were not in the respects he does. Cases involving self-deception also seem better explicable in terms of several, interacting states such as anxiety and suspicion, for example, as opposed to vague belief. ${ }^{12}$

\section{VT from the first-person perspective}

In the previous section, I argued that Juliet's case, and those like it, fail to motivate VT. I did not argue that such cases are incompatible with VT. Furthermore, for all I say so far, it remains an open possibility that there is a case of another kind, which might motivate VT. However, I will now argue that, not only is this not so, but that VT is positively untenable.

VT emerges out of a particular philosophical tradition, which begins with Quine (e.g. 1960) and progresses through Stitch (e.g. 1983), Davidson (e.g. 1984), and Dennett (e.g. 1987), to name a few of its guiding participants. In this tradition, philosophers remain firmly rooted in the third-person perspective when considering what it is for someone to believe something. As we have seen, we are encouraged to think about cases such as Juliet's from an observer's perspective and consider which belief (if any) it is appropriate to attribute to the person in question. This is not to say that only outwardly observable behaviour need be considered relevant to belief attribution. As aforementioned, both Schwitzgebel and Price allow that dispositions to behave 'internally' in certain ways, such as draw certain conclusions etc., are to be included in the believer's dispositional profile. But note that such internal dispositions can be considered from the third-person perspective of the attributor

\footnotetext{
12 See Archer (2013) for a detailed discussion of self-deception.
} 
just as readily as those relating to outwardly observable behaviour. Furthermore, they can be considered from the 'third-person perspective', as I am using the expression, even by the believer themselves. So the distinction between the first and third-person perspective on belief that I am drawing here is orthogonal to the distinction between beliefs that can be attributed using the first-person in the grammatical sense and beliefs that can only be attributed using the grammatical third-person. Rather, it is a distinction that attempts to highlight the janus-faced nature of belief itself. On the one hand, from the third-person perspective, a belief is an item in the world, a psychological state that helps explain the believer's behaviour. On the other hand, from what I am calling the 'first-person perspective', a belief is the believer's view on the world: what the believer takes to be true. On my view, these two faces are related. It is in virtue of understanding that someone's belief is what they take to be true that one can understand their behaving as they do. Nonetheless, it is possible to focus on one face to the exclusion of the other.

Until now, I have concentrated on addressing VT on its own terms, from the third-person perspective. I have argued that even on home ground, cases such as Juliet's fail to motivate VT. But any adequate account of belief clearly needs to accommodate both of belief's two faces. I will now argue that VT is unable to accommodate the first-person perspective on belief, the sense in which one's own belief is what one takes to be true. It is this failure that ultimately undermines VT.

I will consider two questions which, by anybody's lights, one can ask oneself about one's own beliefs. The first is what I will call the 'Deliberative Question'whether to believe that $p$-and the second is what I will call the 'Introspective Question'-whether I believe that $p .{ }^{13} \mathrm{I}$ will identify two difficulties for VT generated by each of these questions.

Although most of our beliefs are not formed as the product of deliberation about whether to believe something, we nonetheless have the capacity to form beliefs in this way and we sometimes do. The first difficulty for VT I will discuss here stems from the fact that deliberation concerning whether to believe that $p$ necessarily has a certain character. When one deliberates about whether to believe that $p$ this question necessarily strikes one as tantamount to the question whether $p$ in the sense that when one considers whether to believe that $p$, necessarily, it is immediately (noninferentially) obvious to one that this question is settled by, and only by, answering the second question, whether $p$. Only epistemic considerations strike one as relevant to whether to believe that $p$. If one is considering whether to believe that all swans are white, for example, this question immediately strikes one as answerable only by determining whether all swans are white. Following Shah (2003), this fact is sometimes known as 'transparency'. The question whether to believe that $p$ is described as 'transparent' to the question whether $p .{ }^{14}$

\footnotetext{
13 As will become clear, I do not intend the use of the term 'introspective' here to imply that I take selfknowledge to involve any form of inner perception. Indeed, I will maintain that in conceptually primary cases one answers the former question in virtue of answering the latter.

14 It is important to note that the transparency of doxastic deliberation is entirely compatible with the fact that, outside of one's conscious awareness, non-epistemic phenomena, such as what one wants to believe, for example, can, and indeed often do, influence what one believes.
} 
Now, the transparency of deliberation concerning whether to believe that $p$ is a fact about what is psychologically possible in an aspect of our doxastic lives that needs accommodating by any satisfactory picture of belief. The problem for VT is that this transparency is a necessary constraint on beliefs formed via deliberation concerning whether to believe that $p$. If one forms one's belief in this way, one's deliberation is necessarily transparent. One can only consider epistemic considerations pertinent to one's question. This is in patent conflict with VT's claim that there is no necessary criterion for possessing any given belief. According to VT, it should be possible for someone who satisfies all of the other envisaged criteria for holding a certain belief, let's say, to form a belief via deliberation concerning whether to believe that $p$ that is not transparent. They could consider non-epistemic reasons such as what they want to believe, for example, as pertinent to their deliberation. But this is not possible.

A second problem for VT emerges when we focus on the moment of concluding one's deliberation concerning whether to believe that $p$. On my view, one has three options; one can conclude one's deliberation:

1. By judging that 'yes, $p$ ', and therein forming the belief that $p$;

2. By judging that 'no, $\sim p$ ' and therein forming the belief that $\sim p$;

3. By withholding belief insofar as one judges one's epistemic reasons to be inconclusive on the matter. ${ }^{15}$

If VT were true, the deliberator themselves could understand that it can be vague whether or not one believes something. Indeed, arguably they would understand this simply in virtue of possessing the concept of belief, which they are employing. Regardless, assuming a case in which the deliberator does understand that it can be vague whether or not one believes something, a fourth option for concluding one's deliberation about whether to believe that $p$ would be possible. One could conclude one's deliberation about whether to believe that $p$ by somehow plumping for vague belief. But what kind of assessment of one's epistemic reasons would justify such a conclusion? As per the transparency thesis I have just discussed, when one concludes one's deliberation about whether to believe that $p$ by forming the belief that $p$, one does so in virtue of answering the question whether $p$ in the affirmative and therein forming the belief that $p$. But what kind of answer to the question whether $p$ would enable one to form a vague belief? If one is unsure whether $p$ this justifies withholding belief, not the formation of a vague belief. So the second difficulty with VT from the first-person perspective is that it requires the possibility of what is in fact an unintelligible conclusion to deliberation concerning whether to believe something.

\footnotetext{
Footnote 14 continued

See Archer (2017) for a defence of the transparency of doxastic deliberation.

15 There are certainly cases in which one concludes one's deliberation about whether to believe that $p$ by thinking something like 'I'm fairly sure that $p$ ', for example. Being 'fairly sure that $p$ ' is arguably formalisable as believing that $p$ to a certain degree. If degrees of belief were a type of vague belief as Schwitzgebel claims, VT would be coherent in the context of deliberation about whether to believe that $p$ in such cases. I set these kinds of cases aside here.
} 
The third problem for VT I will discuss here is generated by the Introspective Question, whether I believe that $p$. Although, in accordance with VT, per impossibile, the fourth possible conclusion just discussed would have to be available to one deliberating about whether to believe that $p$, not all purported cases of vague belief would involve the deliberator concluding their deliberation in this way. Indeed, in the alleged case of vague belief we have been focused on, ex hypothesi, Juliet "finds the case for racial equality compelling". Juliet straightforwardly forms a conclusion of the form 'yes, $p$ ' when deliberating about whether to believe that $p$. But as we have seen, according to VT, despite judging that $p$, Juliet does not therein form the belief that $p$ in so far as she fails to resemble one who believes that the races are intellectually equal in other ways. So, according to VT, if Juliet considers whether she believes that the races are intellectually equal-if she poses herself the Introspective Question-she should think that it is vague whether or not she believes that they are. As VT would have it, Juliet, like everyone else, is in a position to recognise that her judgement that the races are intellectually equal is not sufficient for her believing that they are. Judging that $p$ is only one behavioural output relevant to being classifiable as believing that $p$ : it is neither necessary nor sufficient for believing that $p$. So, according to VT, Juliet is in a position to think the following Moore-paradoxical-like thought:

The races are intellectually equal, but I don't believe that they are simpliciter; it is vague whether or not I believe that they are.

Schwitzgebel (2010, p. 542) intimates that VT has this consequence and attempts to minimise it as "linguistic unnaturalness", claiming that the unnaturalness of traditional Moore-paradoxical statements arguably reflects pragmatic constraints on speech. ${ }^{16}$ However, as Moran (2001, p. 70) points out, this cannot be a satisfactory analysis of what is paradoxical about Moore-paradoxical statements as it is paradoxical even to think ' $p$, but I don't believe it', or, 'I believe that $p$, but $p$ is not true'. The utterance of such a thought is not necessary for the generation of paradox. Similarly, even thinking ' $p$, but I don't believe it simpliciter, it is vague whether or not I believe it' is paradoxical. VT is left owing an explanation of this paradoxicality.

On my view, Moore paradoxicality is explicable in terms of a second kind of transparency. This time, it is not the transparency between the Deliberative Question (whether to believe that $p$ ) and whether $p$ that is relevant, but the transparency between the Introspective Question (whether I believe that $p$ ) and whether $p$. This latter kind of introspective transparency has been much discussed in the selfknowledge literature. ${ }^{17}$ According to 'transparency' theorists about self-knowledge, the question whether I believe that $p$ is transparent to the question whether $p$ in the sense that, in conceptually primary cases, the former question is answerable in virtue of answering the latter question. Like deliberative transparency, introspective transparency is explicable in terms of the thinker comprehending that what it is to

\footnotetext{
16 Searle (1969) (and others since) have explicitly propounded such a view.

17 See, for example, Moran (2001) and Boyle (2009).
} 
believe that $p$ is to take $p$ to be true. Roughly speaking, it is because the thinker understands that whether they believe that $p$ is a question about whether they take $p$ to be true that they can answer the former question in virtue of answering the latter. Introspective transparency explains what is paradoxical in a thought of the form ' $p$, but I don't believe it simpliciter, it is vague whether or not I believe it'. The judgement that $p$ implicitly contains the judgement that one believes that $p$ simpliciter. Hence a contradiction is generated when one adds 'but I don't believe that $p$ simpliciter'.

To claim that in conceptually primary cases one can answer the question whether to believe that $p$ in virtue of answering the question whether $p$ is not to claim that in all cases one knows that one believes that $p$ simply in virtue of judging that $p$. If this were so, we could have made short shrift of Juliet's case. There would have been no doubt that she believes that the races are intellectually equal insofar as-ex hypothesi-she judges this to be the case. Rather, one who believes that $p$ is of course answerable for one's behaviour taken as a whole, as I have already emphasised. In Juliet's case, I have argued that the pattern in her behaviour renders it plausible that she does believe that $p$ in spite of her behaviour that suggests otherwise, which is to be explained in terms of a belief-discordant implicit attitude. Nonetheless, an explanation of her conflicting behaviour is required. And this explanation is required from Juliet's own perspective: to claim that in conceptually primary cases one can answer the question whether I believe that $p$ in virtue of answering the question whether $p$ is not to claim that this is the only way one can come to know about what one believes. As aforementioned, one can treat one's own behaviour as evidence regarding what one believes just as much as anyone else can.

What is important for explaining why we baulk at Moore-paradoxical claims is that transparent self-knowledge of one's beliefs is what we expect of others and ourselves under ordinary circumstances. We expect that one have a certain kind of distinctively first-personal self-knowledge with respect to one's own beliefs. That is, self-knowledge that is had immediately-without appealing to evidence-and authoritatively - in a way that is not prone to the same kinds of mistakes that one is prone to when attributing beliefs to others. But more fundamentally, we expect selfknowledge of one's own beliefs that is non-spectatorial. One is not a mere spectator vis-à-vis one's own belief but rather the author of it: in consciously believing that $p$, one therein appreciates the reasons for which one believes that $p .^{18}$

This brings me to the fourth difficulty for VT I will discuss, which concerns whether the capacity for such transparent self-knowledge is compatible with VT. One might think that, according to VT, in order to know that one believes that $p$ one must always adopt the third-person perspective on oneself. One must always consider whether or not one resembles a believer to a sufficient extent in order to know whether or not one is one. However, Schwitzgebel (2011) maintains that one does have the capacity to know whether or not one believes that $p$ simply by reflecting on whether $p$. On his view, this is one method (amongst several) for coming to know whether one believes something. Of course, according to

\footnotetext{
${ }_{18}$ Moran (see e.g. 2001, p. 33) has emphasised the fundamentality of this feature of self-knowledge.
} 
Schwitzgebel, in cases such as Juliet's transparency fails. That is, Juliet reflects on whether or not the races are intellectually equal, judges that they are and yet does not come to know that she believes that they are simpliciter (because she does not believe this simpliciter). Nonetheless, he maintains that transparency is an 'empirically reliable' process for coming to know what one believes, just as vision is a reliable process for coming to know certain facts about the world, despite one's susceptibility to visual illusions on occasion. However, it is unclear why transparency would be a reliable process for coming to know what one believes if it were not for the conceptual connection between judging and believing that I outlined above. The analogy with vision seems implausible. Vision would presumably be understood to be a reliable process for coming to know certain facts about the world in virtue of the manner in which the visual system is, as a matter of empirical fact, connected up with the rest of the world. But are we to conceive of judgements as simply connected up with beliefs in an analogously brute manner? Insofar as we are, the non-spectatorial aspect of one's first-personal selfknowledge of one's beliefs is certainly lost. On Schwitzgebel's 'empirical' picture of the connection between judging and believing, when one moves from ' $p$ ' to 'I believe that $p$ ', one does so in virtue of one's alienated appreciation that judgements typically issue in beliefs under the right kind of circumstances. One does not do so in virtue of one's appreciation of one's reasons for believing that $p{ }^{19}$

In sum, VT cannot accommodate the first-person perspective on belief; it cannot accommodate the fact that what one believes is what one takes to be true. Symptoms of this fact pop up all over the place. I have discussed four. VT cannot accommodate the necessity of deliberative transparency; it makes little sense in the context of considering what it would be to conclude one's deliberation concerning whether to believe that $p$; it cannot capture what is paradoxical about Moore's Paradox (or Moore-paradoxical-like phenomena); and it seems unable to properly account for our capacity for distinctly first-personal self-knowledge.

Price (1969, p. 302) tacitly acknowledges the tension between VT and the firstperson perspective on belief when he says:

Sometimes we even say such things about ourselves, usually in the past tense.

'I see now that at that time I only half-believed what he told me.' (my italics)

His "usually in the past tense" qualification is revelatory of his unease. I hope I have gone some way here towards spelling out the extent to which unease is justified.

\section{Conclusion}

VT claims that 'believes' is a vague predicate. According to VT, fairly often, the most accurate description of someone's state we can give is to say that it is vague whether or not they believe something. Cases such as Juliet's are supposed to

$\overline{19}$ My thanks to Schwitzgebel for correspondence regarding this matter. 
motivate this conclusion. I have been concerned to show that VT is false. I began by taking VT on its own terms and considering how successful an account of Juliet's case it provides from the third-person perspective. I argued that there is a pattern in Juliet's behaviour, indicative of the normatively problematic nature of her situation, which merely claiming it to be vague whether or not she believes that the races are intellectually equal fails to capture. This pattern, I maintained, is suggestive of Juliet's believing that the races are intellectually equal yet, in addition, possessing a belief-discordant implicit attitude otherwise. I acknowledged that the pattern is not incompatible, from the third-person perspective, with its being vague whether or not Juliet believes the races to be intellectually equal in addition to her having an implicit attitude to the opposite effect. Nonetheless, I argued, Juliet's case fails to motivate VT. Furthermore, I pointed out some of Price's and Schwitzgebel's other cases that appear to fail to motivate VT for similar reasons to Juliet. However, I left it open, at this point, that VT might still be motivated by a case I had not considered. But I then argued that it is when we attempt to take VT seriously from the firstperson perspective on belief that it becomes clear that it is not only unmotivated, but untenable. VT cannot accommodate the necessity of deliberative transparency; it makes little sense in the context of considering what it would be to conclude one's deliberation concerning whether to believe that $p$; it cannot capture what is paradoxical about Moore's Paradox; and it seems unable to properly account for our capacity for distinctly first-personal self-knowledge.

Belief is janus-faced. On the one hand, a belief is the believer's view on the world: what they take to be true. On the other, a belief is an item in the world, a psychological state that helps explain the believer's behaviour. VT was designed with only the second of these two faces in mind and hence is not fit for the purpose of accommodating both as any satisfactory account of belief must.

Acknowledgements I would like to thank Lucy O'Brien, Joseph Schear, Eric Schwitzgebel, and an anonymous referee for this journal for their helpful discussion of the material in this article. I would also like to thank audiences in Osnabrueck, and Southampton.

Open Access This article is distributed under the terms of the Creative Commons Attribution 4.0 International License (http://creativecommons.org/licenses/by/4.0/), which permits unrestricted use, distribution, and reproduction in any medium, provided you give appropriate credit to the original author(s) and the source, provide a link to the Creative Commons license, and indicate if changes were made.

\section{References}

Archer, S. (2013). Nondoxasticism about self-deception. Dialectica, 67(3), 265-282.

Archer, S. (2017). Defending exclusivity. Philosophy and Phenomenological Research, 94(2), 326-341.

Borgoni, C. (2016). Dissonance and irrationality: A criticism of the in-between account of dissonance cases. Pacific Philosophical Quarterly, 97, 48-57.

Boyle, M. (2009). Two kinds of self-knowledge. Philosophy and Phenomenological Research, 78(1), $133-164$.

Davidson, D. (1984). Inquiries into truth and interpretation. Oxford: Clarendon Press.

Dennett, D. (1987). The intentional stance. Cambridge: MIT Press.

Gendler, T. (2008). Alief in action (and reaction). Mind and Language, 23(5), 552-585. 
Hume, D. (1978). In L. Selby-Bigge (Ed.), A Treatise of human nature (Vol. 1), Oxford: Oxford University Press.

Kripke, S. (1979). A puzzle about belief. In A. Margalit (Ed.), Meaning and use. Dordrecht: Reidel.

Levy, N. (2015). Neither fish nor fowl: Implicit attitudes as patchy endorsements. Noûs, 49(4) 800-823.

Mandelbaum, E. (2016). Attitude, inference, association: On the propositional structure of implicit bias. Nous, 50, 629-658.

Montaigne, M. (1957). Essays (D. Frame, Trans.) Paolo Alto: Stanford University Press.

Moran, R. (2001). Authority and estrangement: An essay on self-knowledge. Woodstock: Princeton University Press.

Price, H. (1969). Belief. London: George Allen \& Unwin.

Quine, W. (1960). Word and object. Cambridge: MIT Press.

Rowbottom, D. (2007). "In-between believing" and degrees of belief. Teorema, 26(1), 131-137.

Rowbottom, D. (2016). How might degrees of belief shift? On actions conflicting with professed beliefs. Philosophical Psychology, 29(5), 732-742.

Ryle, G. (1949). The concept of mind. New York: Barnes \& Noble.

Schurz, G. (2002). Ceteris paribus laws: Classification and deconstruction, ceteris paribus laws. In J. Earman et al. (Eds.), Erkenntnis (Vol. 52 (Special Issue), pp. 351-372).

Schwitzgebel, E. (2001). In-between believing. The Philosophical Quarterly, 51(202), 76-82.

Schwitzgebel, E. (2002). A phenomenal dispositional account of belief. Noûs, 36(2), 249-275.

Schwitzgebel, E. (2010). Acting contrary to our professed beliefs, or the gulf between dispositional belief and occurrent judgment. Pacific Philosophical Quarterly, 91, 531-553.

Schwitzgebel, E. (2011). Knowing your own beliefs. Canadian Journal of Philosophy, 35, 41-62.

Searle, J. (1969). Speech acts: An essay in the philosophy of language. Cambridge: Cambridge University Press.

Shah, N. (2003). How truth governs belief. The Philosophical Review, 112(4), 447-482.

Stich, S. (1983). From folk psychology to cognitive science. Cambridge: MIT Press.

Zimmerman, A. (2007). The nature of belief. Journal of Consciousness Studies, 14(11), 61-82. 